\title{
Entrevista a Alejandro Tortolini. Tecnologías, inclusión digital y alfabetización informacional en pandemia (y postpandemia)
}

\author{
Angela Paladino \\ Universidad Nacional de La Plata. Departamento de Bibliotecología, Argentina \\ Micaela Villalba \\ Universidad Nacional de La Plata. Departamento de Bibliotecología, Argentina \\ Matías Miguel \\ Universidad Nacional de La Plata. Departamento de Bibliotecología, Argentina \\ entrevistaspalabraclave@gmail.com
}

Alejandro Tortolini es docente e investigador, especializado en cultura digital, videojuegos y educación, vinculado a la Universidad de San Andrés, la Universidad Tecnológica Nacional y la Fundación Instituto Leloir. También es miembro de la Red Argentina de Periodismo Científico, y actualmente es parte del plantel docente de la materia Inclusión digital y políticas públicas en la Universidad Nacional de José Clemente Paz (UNPAZ).

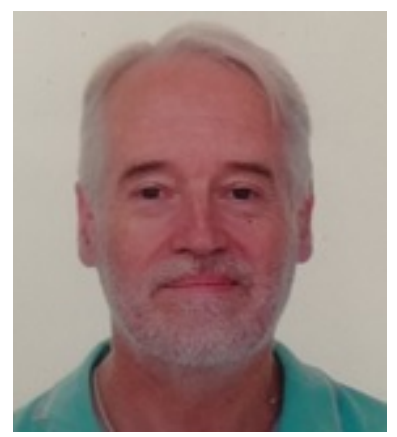

Palabra Clave [PC]: En lo que a su opinión respecta, ęa qué público, o tipos de públicos, parece haber afectado más la brecha digital en este nuevo escenario social generado por la pandemia del COVID-19?

Alejandro Tortolini [AT]: afectó más a quienes no tienen acceso a herramientas que se evidenciaron como imprescindibles, como un equipo para estar conectado a internet (un equipo adecuado), y cuando digo un equipo adecuado sería un equipo que permita participar en las actividades que tienen que ver con la educación, con lo que se ofrece como actividades educativas. No es lo mismo acceder a una plataforma educativa desde un celular que desde una computadora con una conexión de banda ancha. Yo por suerte vivo en un barrio donde hay un proveedor que me puede abastecer de 100 megas de conexión, con capacidad de conexión, y esto se dio de casualidad. Me mudé a un barrio, Almagro, y en este lugar, en esta manzana, había un proveedor que había conectado banda ancha de 100 megas, fibra óptica. Pero hasta no hace mucho vivía en Floresta, donde estas posibilidades no existían, y si estuviera en otro barrio, donde directamente tengo no tengo conexión o una muy mala, esta videoconferencia no podríamos estar haciéndola. Si tengo que acceder a materiales que el Ministerio de Educación de la Nación o una provincia diseña de determinada forma, 
plantea actividades interactivas y demás, y mi única forma de conectarme es a través de un teléfono celular, mis posibilidades van a estar limitadas.

Los más perjudicados, respondiendo a la pregunta concretamente, son aquellos que no tienen las herramientas y la velocidad de conexión necesaria para manejarse fluidamente.

Ahora, que uno tenga estas herramientas ideales tampoco garantiza que salga todo bien, por lo que ahí hay otro aspecto que seguramente después vamos a volver a tocar, que tiene que ver con el conocimiento de las personas de esas herramientas, algo que se vio muchísimo en el ámbito educativo, y sobre todo a nivel de educación superior, que fue que muchos docentes no estaban capacitados para usar, por ejemplo, herramientas o plataformas de videoconferencia, porque nunca lo habían hecho, y se encontraron con que tenían que desarrollar una clase a través de una videoconferencia, por lo que ahí también hubo perjudicados, porque tuvieron que aprender rápido y no venían preparados.

Entonces, en primer lugar los más perjudicados son aquellos que no tenían las herramientas adecuadas para conectarse por internet a los recursos educativos. En segundo lugar, aquellos que no tienen conocimientos. Entonces, obviamente, quienes van a ser los peores afectados son los que no tienen herramientas y los conocimientos. Después hay todo un arco en el otro extremo que, podemos decir, son los que tienen la conexión, conocimiento y, lo que yo llamo, fluidez tecnológica.

\section{PC: ¿Cuáles son los nuevos desafíos a los que deben hacer frente las personas que necesariamente debieron modificar sus hábitos hacia la virtualidad?}

AT: Los desafíos son enormes y muy variados. Vamos a agrupar, porque acá estamos en una situación en la que todo el mundo se tuvo que adaptar.

En primer lugar, las familias, todos, nos tuvimos que adaptar a quedarnos en nuestras casas, ese fue el primer desafío porque no estábamos acostumbrados a estar y convivir todo el día en casa. Recuerdo una vez que una profesional me contaba que se estaba por ir de vacaciones, y el esposo, un abogado exitoso, tenía la posibilidad de alquilar una casa un mes en la costa, y los problemas surgían los primeros días de convivencia porque no estaban acostumbrados a verse todo el día: los dos salían a la mañana a trabajar, las hijas en el colegio y la realidad es que en la mayoría de los casos, pensemos ¿cuántas son las horas de convivencia real con los demás? Muchas veces estamos más tiempo en nuestros trabajos que con nuestras familias, pero ahora todos estuvimos obligados a quedarnos en un lugar con nuestros seres queridos.

En segundo lugar, la distribución de los recursos tecnológicos que nos permitían, en este caso, educarnos, pero además ahora había que trabajar. A muchos les ha pasado tener que turnarse. Mi mujer, tomando un examen ayer, me contaba: "tuve alumnos que me plantearon que tuvieron que esperar y acordar un horario distinto para tomar el examen porque el padre estaba usando la computadora para trabajar". Entonces, se da un desafío de la alternancia en el uso de las tecnologías, en cuanto a convivencia, es la organización de las tareas de la casa: uno a veces tiene que organizar las tareas que tienen que ver con la educación con el tema de la comida y la limpieza.

Además, los equipos que se rompen, en general, son los artefactos con los que nosotros nos manejamos porque no están pensados para el uso intensivo que se les está dando ahora. Un montón de gente reporta cosas que se rompen. Las cosas en las casas se rompen mucho más seguido, y hay toda una adaptación que ha generado enormes desafíos.

Pero yendo a lo que tiene que ver con la educación a distancia, que es un poco el centro de este diálogo, sin duda tiene que ver con la adaptación al uso intensivo de estas nuevas herramientas. No todo el mundo estaba preparado. Mencionaba lo de educación superior porque creo que es donde más se vio. En las universidades, la costumbre es la clase magistral, más allá que sabemos que hay docentes que trabajan muy bien con lo multimedial, con lo interactivo y con las herramientas digitales. Hay docentes que hacen maravillas, pero sabemos que la mayoría está acostumbrado a dar la clase ante un grupo enorme de alumnos, y después los 
encargados de trabajos prácticos o ayudantes de cátedra, se ocupan de ir apoyando lo visto en los teóricos y llevando la materia.

A mí me ha pasado como docente. La UNPAZ tenía un campus virtual que funcionaba muy bien pero, paralelamente, en otra universidad empecé a cursar materias en otra carrera, y era una en la que nunca se vieron relacionados con el arte multimedial. Nunca se habían planteado tener que hacer cosas a distancia, es más una carrera eminentemente proyectual, donde uno tiene que armar dispositivos, crear figuras, tienen que hacer cosas con alambre, con cartón, y de repente cayó la pandemia ni siquiera habían planteado la posibilidad de tener que dar clases de esta manera, nadie pensó esto. Gente en sistemas me decía esto: "tuvimos que inventar manuales nuevos" porque nadie había pensado en la posibilidad de que la gente no pudiera ir al lugar de trabajo, impensable. Siempre se asumió que la gente iba estar en la oficina, en la fábrica, en el frigorífico o en el hospital trabajando, bueno ahora la gente no puede acceder. Tuvieron que empezar a hacer protocolos, bueno hay que trabajar a distancia, abrirle a todos un usuario, tener que abrir el servidor, ampliar las estructuras, un operativo enorme.

Entonces, me parece que la cantidad de desafíos fueron y siguen siendo enormes. En lo educativo todos imaginamos el aula, pero nadie imaginaba la imposibilidad de acceder al aula y del contacto cara a cara, físico. Todo eso es un desafío enorme. El otro día asistí a un webinario excelente que dio Flavia Terigi, ${ }^{1}$ una referente en educación, y lo que ella planteaba era: "miren, todo bien, pero esto no es educación, estamos dando clases virtuales, pero esto no es educación”. Y planteaba como un enorme desafío el desarrollar una didáctica para las clases a distancia en este contexto, y no una didáctica de un campus virtual donde yo subo una actividad y, con un Moodle, "subir, poner un foro, nos presentamos...". No es eso. Yo creo que en todos los niveles, el principal desafío, y del que se ha hablado bastante poco, lo hablan los docentes, no las autoridades educativas, o por lo menos, no con la fuerza que debería hablarse, es cómo retener a las y los alumnos en la escuela, en la universidad. Yo me pregunto cuáles van a ser los niveles de abandono en este contexto. Hablando con docentes en redes sociales, empezó a pasar que muchos comentaban en esto, “¿y si yo no logro que las y los alumnos se conecten o que hagan la actividad?". Pasó que, al comienzo de la pandemia, en muchos establecimientos y muchas instituciones (cuando yo hablo de escuela hablo en general de todo lo que tiene que ver con el ámbito en donde se da el acto, el acto pedagógico) dijeron: "bueno, pandemia, subamos y hagamos que las chicas y los chicos sigan la actividad" y entonces mandaron tarea, tarea y tarea, montones de tarea, inundación de tarea. La familia volviéndose loca porque tenían que realizar los quehaceres de una casa llena de la gente, que se suponía que en determinados horarios se iba, y además había que hacer tarea de todas las materias. Poco a poco, las y los docentes se dieron cuenta de que no era la forma. Entonces empezaron a dosificar, porque los padres y las madres dijeron: "no inunden de tarea" y ahí fue cuando se comenzó a hacer un poco más de sintonía fina, y esto no es comentario de colega docente sino de familia, pero la verdad es que estábamos mucho mejor cuando el nivel de tarea es menor, nos acomodamos todos y, listo, perfecto. Me parece que ahí hubo una cosa muy importante de adaptación mutua.

Esos son los principales desafíos que se vieron hasta ahora. Desafíos de conexión, pero también de hábitos, de convivencia, de acuerdos en horarios y en tiempos. Y me parece que todavía estamos lejos de tenerlo resuelto. Fijate vos que hasta el tema de la vuelta es otro desafío enorme, para el cual no hay acuerdo, y ni a nivel mundial, no es que le pasa a la Argentina, con la pandemia estamos hablando de un fenómeno mundial y estamos hablando de desafíos en todo el mundo. Lo que pasa en otros países, en España y Estados Unidos, es que los docentes están preocupadísimos porque quieren forzarlos a volver a las clases. Ayer leía que en España va a haber sanciones para escuelas o docentes que no vuelvan a clases, también para alumnos. Obviamente se va a aplicar el reglamento de inasistencia, pero la gente tiene miedo de morirse, no es poco.

Otra problemática es que, por ejemplo, en los ámbitos laborales te dan una silla más o menos cómoda porque saben que vas a estar trabajando ocho horas sentado. Yo los primeros días en mí casa, estaba frente a la computadora en una silla plegable de metal. No me quedé lisiado de casualidad, y ahora más o menos tengo 
una silla un poco más cómoda, pero tampoco es la silla que yo tengo en mi escritorio de trabajo, que es una acolchada, diseñada para que uno esté sentado ocho horas por día.

Además, muchos descubrieron, recordé, lo tensionante que es una videoconferencia. Esto que vos estás hablando y fijándote cómo salís, que no te camine el gato por el escritorio y que se escuche, o que no se escuche pensando: “¿a ver qué dije?”. Muchas personas me comentaron que daban una clase por videoconferencia y terminaban agotados. Hay una carga de tensión grande, no es costumbre enseñar de esta manera, creo que son cosas que uno va aprendiendo y va resolviendo, y para las que nadie estaba preparado. Realmente, seguimos aprendiendo sobre la marcha.

\section{PC: En el plano educativo, ¿cómo cree usted que la situación actual desafió a los diseños curriculares de} los distintos niveles educativos, especialmente al universitario?

AT: No sé si el desafío pasa por lo curricular, me parece que el gran desafío pasa por la didáctica. Lo digo por eso que comenté, que me gustó muchísimo, lo que dijo Terigi, porque dio en el blanco. En lo curricular, no creo que haya un desafío en lo inmediato, y pienso en las materias que doy, que son las que más conozco. Lo que voy a hacer a partir de esta pandemia es incorporar algunos fenómenos nuevos. En este momento doy clases en la catedra Inclusión digital y politicas públicas de la UNPAZ y voy a reforzar algunos contenidos. Pero ya lo veníamos hablando, porque justamente en esa materia lo que pretendo es que alumnos y alumnas se lleven herramientas para pensar críticamente el tema de la inclusión digital y las políticas públicas. No hacemos una mera revisión de lo que hacen los países, sino que analizamos el capitalismo de plataformas, los criterios con que nos dicen cuáles van a ser las habilidades del siglo XXI, y en quiénes son los actores interesados en que las habilidades sean unas y no otras. Sí, creo que voy a tener ejemplos fantásticos, a partir de esta pandemia, de algunas de las cosas que nosotros vemos, como la concentración económica en manos de gigantes de las tecnologías. Temas que ahora justamente se están empezando a ver con más claridad. Por estos días, hubo audiencias en el Congreso de los Estados Unidos, a las que tuvieron que asistir los directivos máximos de las empresas tecnológicas más grandes. Los dueños de esas empresas tecnológicas, con esta pandemia, han tenido un crecimiento en sus ingresos que es impresionante, es escandaloso. Si eran multimillonarios, ahora son mucho más multimillonarios. Insisto, no sé si desde lo curricular va a haber grandes modificaciones, pero sí creo que es imprescindible una adaptación y una creación de didácticas nuevas en este contexto, que nadie imaginó. Una cosa es suponer que la semana siguiente no vamos a tener clases, y nos vamos a arreglar subiendo los materiales a la plataforma y en 15 días, calculamos, lo vamos a tener resuelto. Pero no. Desde marzo estamos así. Ya no alcanza con decir "bueno, lo subo a la plataforma". No, hay que enseñar de una manera nueva, de una forma diferente. Hasta que no haya una vacuna efectiva, no va a haber grandes modificaciones. El tema de la presencialidad pero, ¿en qué condiciones? En las escuelas a las que fui como facilitador, había una maestra con 25 alumnos, ¿cómo implementas la distancia social ahí? En un aula así, he dado clases en el CBC, hace años. Los alumnos que llegaban tarde tenían que ver la clase por la ventana. En La Plata, pensá en el aula en la cual estás. ¿Cómo haces para meter a todos dejando dos metros? En el CBC tuve cursos de 120 personas, y tenía compañeras que daban en un curso con 300, allá en Paseo Colón. Creo que va a ser necesario replantear un montón de cosas, desde el punto de vista educativo.

PC: ¿Cómo percibe que el escenario actual impactó en la deserción de estudiantes en los diferentes niveles educativos? ¿Cuáles son los factores que, a su entender, influyeron en esta situación?

AT: No tengo cifras. No hay cifras oficiales de deserción. Sí creo que es muy probable que aquellas personas que han tenido problemas de conectividad, seguramente han abandonado. Sobre todo a nivel universitario, porque el Ministerio de Educación repartió cuadernillos y encontró, de alguna forma, la manera de brindar 
contenidos, materiales, se hicieron canales en la Televisión Pública, pero apuntando sobre todo a primaria y secundaria. Creo que debe haber una alta deserción, y sobre todo universitaria, porque además se les suman las complicaciones laborales. Yo me imagino, una chica o un chico, que está empezando una carrera universitaria y que tiene un trabajo que lo obligaba a una tarea presencial. Acá en mi barrio, por ejemplo, han cerrado unos cuantos comercios. En la esquina teníamos una parrilla que trabajaba bárbaro y de hecho, la pareja de mozos, iban muchas veces con su hijito a trabajar, en un local chico, donde es imposible mantener distanciamiento social, un local angosto. Gente buenísima, se comía riquísimo, era un punto de referencia del barrio pero tuvieron que cerrar. No tuvieron la posibilidad de hacer delivery o no pudieron implementarlo. Tenían mozo, más allá de este matrimonio, un muchacho jovencito. Ese pibe, estudiando en la facultad, se quedó sin trabajo, y lo primero que le va a pasar es tener, además de la dificultad laboral, dificultad para seguir estudiando.

Yo creo, y lo he visto por esta carrera que empecé a cursar, que a más de uno se le complicó el tema de resolver las cosas a distancia: lo que tiene que ver con cómo acceder a la plataforma, cómo entender los temas. Hay temas que son muy difíciles de entender si no hay una adecuada preparación de los materiales, y este es otro tema también. No todo el mundo está preparado para hacer materiales entendibles como para ser usados a distancia. Ya lo hemos visto, hay gente que cree que la educación se resuelve recurriendo a voluntarios, olvidándose que hay una formación específica para cada cosa. Esto también demostró que no cualquiera puede enseñar, no cualquiera puede explicar. Ha pasado con la familia que tiene que explicar los temas a sus hijas e hijos pero no es fácil explicar una materia, porque no es solamente conocer el tema. Hay ingenieros que no pueden explicar matemática a los hijos ¿Por qué? Porque no saben de didáctica de la matemática. El ser docente no es una carrera de descarte, hay una profesionalización que implica ser un profesional de la educación. Vos tenes las herramientas, aprendes las herramientas para educar, ¿pero cómo le enseñas a una chica o un chico matemática? ¿cómo le enseño lengua? No se hace de cualquier manera, y no se hace porque sí. Se estudia, uno se forma, se prepara. Ustedes con su carrera se están formando, no cualquiera puede ser licenciado o licenciada en bibliotecología. Entonces, ha pasado esto también, ha habido dificultades en la forma de transmitir el conocimiento.

Me parece que, volviendo a la pregunta, repito, no tengo cifras concretas de deserción, pero que va a haber niveles importantes de deserción por todas estas cuestiones. Por primera vez, el dispositivo tecnológico es imprescindible en educación. Ahora, debés tener la posibilidad de conectarte a través de internet con alguien que te tiene que enseñar, y si alguno de los dos tiene deficiencias en esa conexión que se establece, lo más probable es que alguien termine abandonando.

\section{PC: ¿Qué nuevas estrategias desde las instituciones pudiste observar que se desarrollaron para subsanar las problemáticas relacionadas con la inclusión digital?}

AT: Se vio de todo. Por supuesto, esto mostró que quienes mejor se desempeñaron fueron aquellas instituciones que ya venían trabajando en una semipresencialidad. Hay colegios que ya venían trabajando con una plataforma virtual.

Recuerdo que, trabajando en escuela pública, había dos maestras que ya usaban las herramientas de Google, concretamente, porque les resultaba práctico poder corregir usando el celular mientras viajaban en colectivo. Tenían un viaje largo y la escuela tenía las computadoras que se le habían dado a pibas y pibes, y estas dos chicas jóvenes estaban felices con el plan porque, ya de hecho, ellas las usaban: les hacían hacer videos con la computadora, usaban las herramientas de Google, tenían que usar también las herramientas de Edmodo, ${ }^{2}$ porque desde el Ministerio se pedía usarlo. Esto era en la Ciudad de Buenos Aires. Y otras cosas las hacían por las herramientas de Google, entonces ya había una práctica. Todo esto no les debe haber sorprendido. Pero había otras maestras, que eran completamente refractarias. Lo mismo ocurre con los colegios. Conozco colegios que ya venían trabajando, teniendo lo virtual como una herramienta más, subían tareas a la plataforma, entonces esos colegios rápidamente se adaptaron. Hay que adaptar todo el plantel 
docente a esta nueva modalidad, a organizar los horarios. Pero por fuera de esa necesidad de organización de las personas, la institución ya venía bien.

Ahora, y esto tiene que ver con lo que decía antes del "saber usar", conozco instituciones, universidades privadas que contrataron herramientas malísimas para enseñar a distancia. Malas, porque usaron herramientas que estaban pensadas para la empresa. Por ejemplo Zoom es una herramienta empresarial, no una herramienta para usarla como la usamos hoy en día. Se realizan videoconferencias para conectar equipos chicos. Con esto, se mostró que era una herramienta muy flexible, hicieron los retoques que tuvieron que hacer, y fue el éxito que conocemos hoy en día. Hay instituciones que han comprado herramientas cerradas, con poca capacidad de ser modulares, y han capacitado mal a los docentes también. Entonces, te encontras con un docente que tiene que dar clases con una herramienta que es mala, y con quien se capacitó mal porque se dieron capacitaciones con poco tiempo. Conozco casos donde se han dado capacitaciones de una hora, mostrando la plataforma, y alguien te dice, tipo clase magistral: "bueno, acá en la pantalla ustedes tienen..." e iban nombrando elementos y no les habilitaron clases de práctica. El primer día, por supuesto, las y los docentes estaban con los pelos parados, todos estresados, fallaban las cosas, había que pedir ayuda, "el botón de compartir pantalla no funciona", "no mira, el botón está acá abajo"... se iba aprendiendo sobre la marcha. Por eso digo, no es solamente el acceso al recurso sino saber usarlo, saber elegir, un tema fundamental me parece, ¿̇cómo evaluamos qué recurso elegir al momento de dar clases de esta manera? Bueno, eso también va a haber que tenerlo en cuenta y formarse para eso también.

\section{PC: En su consideración, ¿cuáles serían las medidas necesarias más adecuadas para que en las escuelas puedan desarrollarse planes en torno a la alfabetización digital?}

AT: Todo lo que tenga que ver con aprender a evaluar críticamente las herramientas. Una cosa que se ve desde el punto de vista de la tecnología, es que se compran herramientas en función de, muchas veces, los intereses o las malas evaluaciones de los funcionarios. Entonces uno se encuentra con que, en determinado lugar, se hace una compra de pizarras digitales, carísimas, poco prácticas. Estuve en una escuela donde la pizarra digital se usaba para proyectar videos nada más, porque está el recurso, pero faltó la capacitación. Hace un tiempo, trabajé en un postítulo en el que se había comprado una herramienta y uno de los módulos no andaba, y no había forma de modificar, ni tocar o de hacer nada, había que esperar a que se renovara el contrato. Uno se encuentra con esas cosas. Si se van a tomar determinadas decisiones que tienen que ver con el abastecimiento, la compra de equipos ¿Quién evalúa? La persona que evalúa ¿Sabe? Esto tiene que ver con aprender el uso crítico.

Una cosa que se vio clarísima en esta pandemia es que falta este tema, la alfabetización digital, que no es solamente el tema de acceder al recurso, sino que tiene que ver con saber usar el recurso, y saber elegirlo. Los anglo-parlantes tienen la palabra literacy como alfabetización, y tienen una palabra que me voló la cabeza cuando la conocí, que se llama numeracy, que es la alfabetización numérica. La alfabetización no es solamente saber leer y escribir. Porque sabemos que hay una escala que va desde saber escribir mamá y papá, hasta apreciar una obra literaria o ser capaces de escribir una obra literaria.

Desde el punto de vista tecnológico, es lo mismo. Yo me consigo una computadora para trabajar, sé que trae una hoja de cálculo y un procesador de texto, perfecto. Lo uso, puedo hacer cuentas y escribir textos. Ahora, cuando yo empiezo a aprender a usarlo, no solamente en lo instrumental, sino en conocer las limitaciones que tiene esa herramienta ¿cómo fue pensada? ¿para qué fue pensada? Puedo elegir mejor. Puedo usar una hoja de cálculo de una empresa que es privativa, que me cobra una licencia por usarla, que no me permite modificar el software, pero de repente conozco que existe lo que se llama software libre, donde puedo tener que pagar o no, y donde yo puedo acceder a ese código para poder modificarlo, por lo que voy a tener más elementos para poder elegir mejor y decir "mira, no me voy a comprar este, me voy a conseguir esto, me lo descargo, 
porque además de que es gratuito, me deja a mí hacer modificaciones que me van a permitir moverme con más comodidad con este software y no con este otro". Eso es alfabetización digital.

La alfabetización digital te permite a vos salir del uso instrumental, hacer cuentas o escribir un texto, a elegir la mejor herramienta para hacer cuentas o escribir un texto, o para hacer un montón de cosas más. Ahí me parece que tenemos que apuntar nosotros. Y esto, nos tiene que dar la oportunidad. Tenemos que aprovechar la oportunidad para empezar a pensar en estas cosas. "Che, pará, tal herramienta ees la única que hay? ¿no hay otras? ¿por qué vamos a usar esta? ¿por qué no usamos esta que es mejor? Cumple, en vez de las tres características de ésta, con seis". Me parece que ahí todos tenemos una gran oportunidad a partir de esta pandemia: si nosotros fortalecemos lo que es alfabetización digital en el uso con criterio, ahí vamos a empezar a obtener mejores resultados. Hagamos lo que hagamos, esto siempre es así, mientras más conocimiento tengo yo de cómo es un fenómeno, más chances tengo de entenderlo, de modificarlo, o de adaptarme a ese fenómeno; y además de este momento, prepararte para el próximo momento, que seguramente va a venir, porque esto no se terminó hoy. A todo nivel, hasta a nivel político mundial. Me parece que llegamos hasta acá de esta forma porque no estamos viviendo bien.

\section{PC: En ese sentido ¿Cuál sería el papel de les profesionales de la información (bibliotecólogues, archivólogues, etc.) en lo que respecta a esa alfabetización digital?}

AT: Esa es la pregunta en lo que tiene que ver con la especialidad de ustedes. Hay gente que dice "pero ahora, todo está en internet ¿para qué va a hacer falta una biblioteca?”. Algunos te cuestionan hasta que haya docentes. Di una charla en 2015 en Santa Fe, en un congreso, donde mi ponencia fue La escuela como lugar de criterios, pero ahora digo "la biblioteca como lugar de criterios".

Cuando se habla de criticidad, la palabra crítica, crítico, viene de krinein, una palabra griega que quiere decir 'cedazo', 'pasar por el colador'. Cuando uno hace crítica, lo que hace es pasar por el colador, quedarse con lo bueno, y dejar que el descarte se vaya. En una época de superabundancia de información, y acá también hago un paréntesis ¿estamos creciendo en información? Sí, y aprovecho para mencionar que nadie habla de la información que se pierde, y se pierde muchísima información, pero eso es otra discusión para otro día. En esta época de infoxicación, como dijo hace algunos años Alfons Cornella, ${ }^{3}$ hoy más que nunca son necesarias personas que se preparen para poder analizar y tamizar la información. Recuerdo que hace unos años en Estados Unidos, me impresionó mucho ver la tarea de bibliotecarios y bibliotecarias que estaban convirtiendo esas bibliotecas en espacios sociales, de sociabilización del conocimiento.

En lo que hace información digital, hoy en día, me parece fundamental el trabajo de las y los bibliotecólogos o bibliotecólogues. Me parece que es indispensable, que se formen, que se alfabeticen digitalmente, que conozcan las herramientas, que proporcionen criterios a quienes tengan que buscar información. La curaduría de contenidos me parece más importante que nunca, porque hoy lo estamos viendo claramente con el problema de las fake news, las noticias falsas. La derecha en este momento, en el mundo, está haciendo un tsunami de información falsa y hemos tenido en esta semana figuras de la televisión que toman dióxido de cloro y dicen que se sienten bien, pero hay que salir a decirles, "miren, no hagan estas locuras". Me parece que hoy más que nunca son necesarios profesionales de la información, y que puedan aportar criterios.

No sé de qué manera se va a reconvertir la biblioteca porque veo que se están cometiendo errores gravísimos. Conozco colegios que han vendido sus bibliotecas. El colegio donde estudió uno de mis hermanos hace unos años vendió su biblioteca, entera, porque ya algunos alumnos no la consultaban. En vez de formar en la lectura y en los criterios de lectura, se optó por desprenderse del formato papel, porque ya nadie lo consultaba y se perdieron obras maravillosas.

El mundo no empezó con internet y lo que nosotros tenemos que tener presente, sobre todo en la situación en la que estamos, es en la necesidad de la sabiduría que no sale solamente de internet. Uno lee noticias hechas por periodistas y se da cuenta de que no han leído, no han buscado, no se han levantado de la silla para hacer 
la investigación. Dicen "como esto no debe estar digitalizado, entonces no lo encuentro en Google, por lo que es un fenómeno que no existe", pero uno sabe que existe. Me ha pasado de tener discusiones con gente que considera que tal fenómeno no existía porque no lo encontraba en internet y vos decís "no, bueno, justamente, hay que ir a una biblioteca, a una hemeroteca".

Creo, retomando la pregunta, que es fundamental que haya bibliotecólogues que puedan aportar criterios de manejo de la información, hoy más que nunca. Tenemos que pensar la manera, tenemos que pensar la forma, sobre todo en este contexto, pero me parece que la selección y la recomendación de contenidos hoy son más importante que nunca.

He trabajado en escuelas, donde la biblioteca era un lugar de alegría. Una de mis hijas se la pasaba en la biblioteca, iba a ayudar, porque la bibliotecaria había logrado convertirla en una especie de club. Entonces, tenían un rato libre y se iban a ayudarla, clasificando, mirando, alguien descubría que este tema o este autor estaba buenísimo, y eso es lo que hay que conseguir, y se consigue, es mentira que no se puede conseguir. Lo que pasa es que muchas veces lleva más trabajo, y esto es lo que se ha visto con la pandemia. Mucha gente también hoy está desesperada porque las escuelas abran, porque no se bancan a hijas e hijos en su casa todo el día. Se pierde la costumbre de proximidad y de prestar atención. A veces me preguntaban cómo había logrado que mis hijas y mi hijo leyeran. Un compañero me decía una vez “yo no logro que mi nena lea” y yo le pregunté "che, pero ¿te ve leer? Va a ser difícil que lo entienda como una actividad agradable sino te ve a vos haciéndola como una actividad agradable". Me parece que pasa por ahí. Se puede hacer y una biblioteca puede ser un gran lugar. Trabajé una vez en una escuela que tenía una biblioteca lindísima, con mesas de colores, habían seleccionado unos libros hermosísimos, y era un lugar lindo para estar. Veías a las pibas y pibes, y la pasaban bien, y el bibliotecario les recomendaba cosas. Pero claro, tenés que dedicar tiempo para generar espacios así. Por eso me enoja mucho cuando en las escuelas se nombran maestros o maestras para las bibliotecas porque hay profesionales, y eso es una lucha que hay que dar, que hay que combatir activamente. Hoy es un momento muy propicio, por la cantidad enorme de información berreta que está circulando ¿Cómo que no son necesarios? Son más necesarios que nunca.

\section{PC: ¿Con qué capacidades y/o habilidades cree usted que tendría que contar un docente e investigador para afrontar este nuevo contexto digital de manera satisfactoria?}

AT: Primero, vamos a hablar de las habilidades generales, y después vamos a hablar de las habilidades digitales, porque ese es un tema.

Principalmente, todo buen investigador tiene que formarse en la evaluación de información, y esto tiene que ver con la formación y tiene que ver con la práctica. Todos sabemos que cuando uno empieza la facultad tiene un manejo de información determinado y, después de cinco años, uno mismo ya se da cuenta de que elige mejor, que tiene más criterios para seleccionar y que es más eficiente en las búsquedas de información.

Hay un camino en formación que dan los profesores pero también hay un camino de desarrollo de habilidades que tienen que ver con la práctica. Obviamente, un docente/investigador tiene que ser aquel que esté formado en las herramientas, como en la práctica de esas herramientas y haber acumulado experiencia en la investigación, y ahí es fundamental la compañía de buenos profesores que vayan guiando. Uno se va formando sobre todo en el contacto con pares. La formación de conocimiento es una actividad cooperativa, social, colaborativa. Esto, en lo que hace al docente/investigador.

Con respecto a las habilidades digitales, hay que ser muy criterioso con respecto a lo que hoy se nos venden como las habilidades del siglo XXI, porque esas están basadas en la idea de que hay personas que te vienen a vender cómo va a ser el futuro, que tienen la información precisa de cómo va a ser y que te van a vender un pasaje, y se convierten en imprescindibles. Las habilidades del siglo XXI ya van por la habilidad número 30 que hay que tener: empatía, colaboración, manejo de información, manejo de las herramientas, de actualización permanente. En el gobierno anterior se hablaba de acostumbrarse a vivir en la incertidumbre y lo que nosotros 
aprendemos, por lo menos yo muestro en mi materia, es que hay un discurso de habilidades del siglo XXI que hoy en día se viene desparramado desde el Foro de Davos: ${ }^{4}$ el tema del caso de la revolución industrial 4.0, que es una idea que la vende o la menciona el creador del Foro de Davos, un banquero, Klaus Schwab. ¿Quién es la persona que me está diciendo cómo va a ser el siglo XXI? ¿Qué intereses tiene en venderme esta imagen del siglo XXI, y no otra? Qué casualidad que terminan hablando de un empleado flexible, capaz de adaptarse a trabajos nuevos, que puede aceptar quedarse sin trabajo, porque tiene capacidad de adaptarse a un trabajo nuevo. Se habla de habilidades blandas, aunque ahora el término es agilidad, por ejemplo, porque hay que ser ágiles. El otro día asistí a un seminario por internet, y se les planteaba a los docentes de escuela la importancia de ser ágil, pero ¿cuál es la importancia de ser ágil? ¿ágil para qué? ¿para estar adaptándose cada año a un criterio diferente? ¿Estamos hablando de educación o sino de qué? Hay cosas que no se pueden hacer con agilidad, cosas que se tienen que hacer con lentitud. Vos como profesional sabes que los conocimientos no se adquieren de manera ágil, sino que se adquieren a lo largo de años de lecturas, de formación, de discusión con pares, de machaque.

Entonces, cuando hablamos de habilidades del siglo XXI, tengamos en cuenta que nos están queriendo vender una determinada versión y no otra. Armand Mattelart, el autor del famoso libro Para leer al Pato Donald, ${ }^{5}$ tiene uno hermoso sobre la historia de la sociedad de la información donde una de las primeras cosas que dice es: pero tengamos presente que esta configuración del ahora que tenemos es una, pero no es la única, ni está predeterminada ya que podríamos tener sociedades completamente distintas. Hoy en día vivimos en sociedades permeables por este tipo de tecnologías digitales, porque además estamos inmersos y nos venden permanentemente que el éxito viene asociado a alguna adaptación a las habilidades digitales

Por ende ¿qué habilidades debería tener uno? Bueno, esto que hablábamos hoy, el de ser capaces de verificar si la fuente de información es fiable, chequear si no hay datos que contradigan lo que se nos vende como único, ser capaces de distinguir entre la enorme cantidad de información que anda circulando, saber elegir las herramientas adecuadas para buscar esa información. Por ejemplo, uno puede empezar a pescar y cuando se vuelve un buen pescador, sabe que para atrapar determinado pez debe utilizar cierto anzuelo y carnada, y para otro, tiene que usar otra. Por lo que esa habilidad de elección de herramientas también se va desarrollando.

PC: Al representar a profesionales del campo de la ciencia de la información, consideramos interesante indagar sobre la relevancia que las tecnologías tienen en la vida de las personas, por lo que deseamos preguntarle, desde su perspectiva, la biblioteca como institución social, ¿conlleva o puede afrontar un rol activo en la formación de las personas para mejorar su apropiación de las tecnologías?

AT: Sí, claro, pero no en el sentido de que una bibliotecóloga o bibliotecólogo se ponga a enseñar informática a alguien en la biblioteca, esa no es esa la idea. Desde ese punto de vista va a ser difícil ya que eso lo tiene que enseñar alguien que sepa, pero sí me parece que van a ser fundamentales en ayudar a entender las diferencias entre la calidad de la información. Me parece que ustedes se forman especialmente en lo que creo que es un gran desafío para su carrera, para su profesión, que es encontrar una manera de demostrar que tienen cosas importantes para decir, ya que, creo que tienen muchas cosas importantes para decir. Creo que tienen que pelear por ese espacio de difusión de este rol, en esta sociedad de la información, pero no se habla de quiénes pueden entender y pueden discernir la información, por lo que ese es un espacio que hay que disputar, que hay que pelearlo. Lo mismo pasa con los docentes, que tienen que pelear el espacio de discusión sobre lo que es información y lo que es contenido. A mí me gusta mucho esta distinción, que se puede explicar usando un gráfico, sencillito pero muy lindo, muy claro, donde hay puntos en una hoja, que son datos. Después algunos de esos puntos se unen con líneas, generando información. Luego hay una unidad formando un dibujo, es decir, líneas formando un dibujo, y eso es conocimiento. Lo buscás en internet y aparece. "Dato, información y conocimiento", y vas a ver que en la parte de imágenes te va a aparecer este gráfico de puntos de colores. 
Lo que tenemos en internet son millones de datos y de información, pero no tenemos tanto conocimiento, el conocimiento lo pone el criterio humano, y mucho menos tenemos sabiduría, que es otra cosa, todavía más elevada. La profesión de ustedes me parece que apunta ahí, ustedes saben a dónde orientar a las personas: “a ver venite para este lado, tal autor, tal otro". Lo mismo ocurre en la sociedad digital y me parece que ese es un gran desafío que tienen ustedes como profesionales y que tenemos todos como sociedad, pero en el caso específico suyo me parece que es fundamental, y es un espacio que tienen que pelear con pleno derecho, en la sociedad del conocimiento, donde tenemos que estar todos los que trabajamos por el conocimiento.

PC: ¿Qué cambios piensa que deberían darse para una mejor preparación del sistema educativo si volvieran a darse situaciones similares a esta que atravesamos? ¿O para los nuevos escenarios post pandemia? y ¿̇de qué manera cree que se podrían articular las instituciones educativas y las bibliotecas para desarrollar posibles planes de contingencia?

AT: Medidas inmediatas, porque primero me parece que hay que encarar seriamente el problema de la conectividad, y cuando digo seriamente, me estoy refiriendo a un consenso amplio, empezando por los funcionarios, sobre lo que debería ser una adecuada velocidad de conexión y una adecuada infraestructura de conectividad. Es muy común ver que los máximos responsables de la educación a nivel nacional, provincial, en todos los países, no tienen idea de lo que es una velocidad adecuada de conectividad. Digo, en nuestro país se ve clarísimo. Te hablan de tantos gigas necesarios, pero vos ya sabes, por ejemplo, si ves videos en YouTube, con qué velocidad de conexión tenes que contar para poder ver un video de forma decente. Imaginate eso en una escuela que tiene tres o cuatro turnos, o en el caso de las escuelas rurales, ¿qué hacés? ¿les vas a dar conexión satelital? Hasta he conocido casos de gente que en ciudades importantes han tenido una conectividad pésima.

También es importante reconocer que la conectividad hace que se quede gente afuera ¿vamos a tolerar que haya gente que se quede afuera de la educación por el hecho de que está viviendo en el campo, en la montaña? De última, la gran cuestión es esta, ¿un país para todos o un país para algunos? Entonces, el tema de la conectividad reveló que es un tema fundamental pues, si la gente no puede trasladarse, no puede reunirse, tiene que tener conectividad.

Por eso, en primer lugar, el tema es ponernos de acuerdo para realmente desarrollar una conectividad a nivel nacional, en todas las regiones.

En segundo lugar, desde el punto de vista pedagógico, adaptarse a la forma de enseñar en esta modalidad semipresencial, o directamente $100 \%$ a distancia, lo que tiene que ver con lo que hablábamos antes, sobre no solamente adaptar los contenidos sino, sobre todo, adaptar la didáctica. Desarrollar fuertemente una didáctica de la enseñanza a distancia que involucre la posibilidad de videoconferencias y la necesidad de trabajar sin videoconferencias. La cuestión entonces sería ¿cómo preparo los contenidos para que sean atractivos e interesantes, entendibles? Es muy difícil preparar un contenido así, pero se aprende a hacerlo. Entonces uno no puede dar nada por supuesto, tiene que adaptarse al nivel más bajo asumible, y tiene que explicar a veces cosas que dan por supuestas. "No, mira, la diferencia en un archivo entre guardar, y guardar cómo es...”. A veces tenes que explicar eso porque, por ahí, al usuario ya experimentado le parece básico, pero a la persona que no tiene demasiada práctica no le resulta tan básico. Entonces me parece que el tema de la conectividad, el de la didáctica, el de la adaptación de los contenidos va a ser fundamental, y también vamos a tener que prepararnos para lo peor, porque no va a haber ningún tipo de clase presencial en un tiempo. Veníamos de presencial al 100\%, y ahora estamos en presencial 0. Vamos a tener que encontrar las herramientas adecuadas y prepararlas para lo que se transita entre estos dos extremos.

En lo que respecta a la manera de articular a las instituciones educativas y las bibliotecas para desarrollar posibles planes de contingencia, creo que las instituciones educativas deberían consultar a los profesionales de la información en la elaboración de materiales, y más allá de las meras búsquedas de bibliografía. Me parece que hace falta un enorme trabajo conjunto, sobre todo para aprovechar las mejores experiencias 
educativas, y a aquel que es más experimentado sobre lo que tiene que ver con esta nueva forma de enseñar y de aprender. Me parece que el trabajo interdisciplinario, multidisciplinario, va a ser fundamental, y que las instituciones educativas tienen que ponerse a trabajar con las y los bibliotecólogos, o bibliotecólogues, que son más necesarios que nunca. Acá no puede quedar nadie afuera, en lo que hace a la educación, y en lo que hace al manejo de la información, porque me parece que dejar la profesión de ustedes fuera es un error que se va a pagar caro.

\section{PC: Desde las políticas públicas, ¿cuáles son las que han aportado para enfrentar la problemática de la brecha digital? ¿Qué balance puede hacer y cuáles son sus expectativas respecto a políticas futuras para nuestro país en este sentido?}

AT: Me parece que tiene que ver con lo que hablamos antes, sobre que esto agarró a algunos sectores de la política mejor preparados que otros. Pero, en general, desde el punto de vista de las políticas educativas, me parece que nadie estaba preparado para esto, evidentemente, porque uno ve que hay desorientación educativa en todos los países. Basta con ver los debates y los ejemplos que hay sobre la reapertura de las escuelas, donde uno se encuentra con que se han cometido errores graves, como países que las han abierto y, a los quince días, han tenido que volver a cerrarlas porque tuvieron centenares de contagios. Sin embargo, uno ve también decisiones acertadas que han puesto sobre la mesa la importancia de la conectividad, y de acordar formas mixtas de enseñar, con una mezcla entre la presencia absoluta y la ausencia absoluta, o sino semipresencial, teniendo en cuenta el tema de la necesidad de desarrollar didácticas especiales que mencionaba muy bien Terigi.

También uno encuentra mucho fenómeno de desorientación. El otro día vi el caso de la Universidad de Córdoba sobre el tema del reconocimiento facial para controlar la presencia o ausencia de estudiantes, y me sorprendió la decisión del Consejo Interuniversitario Nacional, el CIN, ${ }^{6}$ en aprobar un control por reconocimiento facial para los exámenes, sin tener presente que a nivel mundial esto está muy discutido y debatido. Muchos países que habían implementado este sistema se están echando para atrás. En Argentina, donde hemos vivido la dictadura que vivimos. Me parece que a veces se cae en lo que el autor Evgeni Morozov llama como solucionismo tecnológico, ${ }^{7}$ donde tenés la solución y ves a qué problema la podes aplicar. A ellos les pareció una buena idea, pero ¿pensamos realmente los pro y los contra?, ¿por qué no hablamos del pacto pedagógico entre docente y alumno?, ¿por qué no reforzamos esas cosas? Hay otras formas de asegurarse el examen honesto, por llamarlo de alguna forma.

Me parece que todavía todos estamos bastante desorientados. Algunos tenemos certezas en algunas cosas, sabemos que tiene que haber conectividad pero ¿cómo tiene que ser? ¿a qué precio? ¿tiene que haber un monopolio de la conectividad? ¿tiene que haber competencia entre empresas? ¿o tiene que haber participación estatal? Todos los días estamos viendo debates sobre cuál debe ser el rol del Estado. Afortunadamente, esta pandemia demostró que la presencia del Estado es importantísima y en este tipo de cuestiones va a ser fundamental. Pero, ¿todas las decisiones que están tomando son adecuadas? No, yo creo que no, ya que me llama la atención que en algunas cosas no haya un poco más de consulta, como en el tema del reconocimiento facial. Hay instituciones, como la Fundación Vía Libre, ${ }^{8}$ donde hay gente que viene trabajando hace años a favor del conocimiento libre y que, de hecho, ha tenido que hacer presentaciones judiciales en algunos otros temas donde se han avanzado sobre los derechos de las personas. Es muy fácil olvidar que las tecnologías afectan derechos pero hay que tener eso siempre presente y consultar a la gente que sabe.

Siempre va a ser disparejo, no solamente para nuestro país, sino que está pasando a nivel mundial. Por supuesto, los países que lo están haciendo un poco mejor son aquellos que son más igualitarios, donde a los ciudadanos se los consulta más, donde tienen más presencia. Igual, también se trata de países con población 
más chica, a veces, o con una tradición de intervención ciudadana más grande. No es casual que, a pesar de que han hecho macanas en este contexto de pandemia también, Europa está mucho más avanzada que Estados Unidos en cuanto a lo digital, por ejemplo, y ni hablar de nosotros. Los primeros problemas que tuvieron las grandes corporaciones tecnológicas sobre derechos ciudadanos, los tuvieron en Europa, no en Estados Unidos. Como, por ejemplo, recuerdo el caso de Google Street. ${ }^{9}$ Es el proyecto donde un auto con un grupo de cámaras arriba del techo va fotografiando, así vos usas el street view y vas viendo como si fueras caminando por la calle. En Estados Unidos lo vieron bien pero en Europa, Alemania concretamente, fue uno de los primeros países en decirles "che, para, pasó tu auto, me sacó una foto, y yo no autoricé que me sacaran ninguna foto". Más allá de que el auto, por ahí justo, fotografiaba a alguna persona media comprometida, más de uno dijeron, "che, ¿quién les dio permiso a ustedes para sacarme una foto?” Entonces se hicieron juicios y se ganaron, o se pusieron multas, y ahí tenes un avance tecnológico que no previó el derecho de la persona.

Agradecemos a Alejandro Tortolini su predisposición para efectuar esta entrevista que ha resultado por demás enriquecedora. ¡Muchas gracias por su tiempo y gentileza!

\section{Notas}

1 Licenciada en ciencias de la educación (UBA). Decana del Instituto del Desarrollo Humano en la Universidad Nacional de General Sarmiento.

2 Edmodo (https://new.edmodo.com/) es una plataforma educativa y gratuita que emula el funcionamiento de una red social al permitir la comunicación entre padres, alumnos y profesores en un entorno cerrado y privado a modo de microblogging.

3 Fundador de Infonomia y el Institute of Next (https://www.instituteofnext.com/), una compañía de servicios de innovación fundada en el 2000.

4 El Foro Económico Mundial (https://es.weforum.org/) es una organización sin ánimo de lucro dedicada a promover debates públicos sobre asuntos globales. Sus sesiones se celebran con una periodicidad anual y tienen lugar en enero en la ciudad suiza de Davos, lo que ha dado a esta organización el nombre informal de "Foro de Davos".

5 Libro publicado en 1971, por Ariel Dorfman y Armand Mattelart, donde se analizan las historietas cómicas publicadas por Walt Disney en el mercado latinoamericano.

6 El Consejo Interuniversitario Nacional (https://www.cin.edu.ar/institucional/) tiene funciones de coordinación, consulta y propuesta de políticas y estrategias de desarrollo universitario y promoción de actividades de interés para el sistema público de educación superior. Además es el órgano de consulta obligada en la toma de decisiones de trascendencia para el sistema universitario.

7 Concepto planteado por Evgeny Morozov en su libro La locura del solucionismo tecnológico (https://books.google.com. ar/books?id=tJnNCgAAQBAJ\&lpg=PP1\&hl=es\&pg=PP1\#v=onepage\&q\&f=false), publicado en el 2015.

8 Fundación Vía Libre: defendemos derechos fundamentales en el entorno digital. Para más información: https://www .vialibre.org.ar/

9 Google Street View (https://www.google.com/intl/es/streetview/) es una presentación de Google maps y Google earth que proporciona panorámicas a nivel de calle, permitiendo a les usuaries ver partes de las ciudades seleccionadas y áreas metropolitanas circundantes. Se introdujo en los Estados Unidos el día 25 de mayo de 2007. 